\title{
Effects of Annealing on Magnetic Properties of Amorphous and Nano crystal line $\left(\mathrm{Fe}_{0.5} \mathrm{Co}_{0.5}\right)_{73.5} \mathrm{Cu}_{1} \mathrm{Nb}_{3} \mathrm{Si}_{13.5} \mathrm{~B}_{9}$ Wires
}

\author{
Yin-feng Li*, Cheng-lin Wang, Jian-sheng Qiao,and Xiao-long Wang \\ Laboratory of Electromagnetic Transport Materials, Xingtai University, \\ No.88 Quan Bei Dong Da Jie, 054001 Xingtai, China \\ ${ }^{*}$ Corresponding author
}

Keywords: Amorphous and Nanocrystalline Wire, Thermal Treatment, Permeability Spectrum.

\begin{abstract}
Amorphous $\left(\mathrm{Fe}_{0.5} \mathrm{Co}_{0.5}\right)_{73.5} \mathrm{Cu}_{1} \mathrm{Nb}_{3} \mathrm{Si}_{13.5} \mathrm{~B}_{9}$ wires were submitted to the thermal treatment of Joule-heating at current $\left(j_{a}=26-45.5 \mathrm{~A} / \mathrm{mm}^{2}\right)$ and time $(t=20-600 \mathrm{~s})$. The effects of annealing on the magnetic properties has been investigated in order to improve the soft magnetic properties by the measurements of longitudinal hysteresis loop and the circular permeability, $\mu=\mu^{\prime}-\mathrm{j} \mu^{\prime \prime}$, determined from the measurements of impedance, $Z=R+\mathrm{j} X$, as functions of frequency $\left(f=10-10^{5} \mathrm{~Hz}\right)$. We found that the most outstanding soft magnetic properties were observed in samples annealed at $j_{a}=32$ - $36 \mathrm{~A} / \mathrm{mm}^{2}$ for $20 \mathrm{~s}$ due to the nanocrystallization. On the other hand, all samples exhibit the relaxation-type feature of permeability spectrum. In addition, from the changes of circular permeability with the annealing time, we can conclude that the optimum annealing condition to acquire best magnetic soft properties is a longer or a shorter time for the amorphous or the nanocrystalline alloy, respectively.
\end{abstract}

\section{Introduction}

Fe-based amorphous and nanocrystalline alloys have been one of the most attractive topics in studying of soft magnetic materials. Compared with the traditional Si-steel or soft ferrite, these alloys exhibit good stability due to higher Curie temperature and lower energy loss as well as superior soft magnetic properties such as high permeability, low coercivity[1-3]. Especially, the substitution of Co for $\mathrm{Fe}$ in the Finemet alloys can elevate largely the Curie temperature above $150^{\circ} \mathrm{C}$, so it has been the candidate in the application of high temperature and high frequency[4,5]. Magnetic spectrum refers to the frequency-dependence of AC permeability from domain wall displacements at low field region. Generally, there are two kinds of domain wall resonance (DWR): the type of resonance and the one of relaxation corresponding to the case of small or large damping factor, respectively. Therefore, the complex permeability spectrum can properly demonstrate the feature of AC magnetic properties of the materials. In this work, we'll report the effects of Joule-heating on the $\mathrm{DC}$ and $\mathrm{AC}$ magnetic properties of $\left(\mathrm{Fe}_{0.5} \mathrm{Co}_{0.5}\right)_{73.5} \mathrm{Cu}_{1} \mathrm{Nb}_{3} \mathrm{Si}_{13.5} \mathrm{~B}_{9}$ alloy.

\section{Experiments}

Amorphous $(\mathrm{Fe} 0.5 \mathrm{Co} 0.5) 73.5 \mathrm{Cu} 1 \mathrm{Nb} 3 \mathrm{Si13} .5 \mathrm{~B} 9$ wire with diameter $2 \mathrm{r} 0=0.14 \mathrm{~mm}$ was produced by in-rotating-water quenching technique. Some pieces of samples $(15 \mathrm{~cm}$ in length) were cut for heat treatment. The samples were annealed by different $\mathrm{DC}$ current $(\mathrm{ja}=26-45.5 \mathrm{~A} / \mathrm{mm} 2)$ for $20 \mathrm{~s}$ in air. In addition, two series of samples were treated by ja $=29.2$ and $35.7 \mathrm{~A} / \mathrm{mm} 2$, respectively, at the range of $\mathrm{t}=20-600 \mathrm{~s}$ in order to study the annealing-time effects. Longitudinal hysteresis $\mathrm{M}(\mathrm{H})$ loop was measured by a system of flux-meter with a searching coil and a solenoid $((2 \mathrm{~cm}$ and $60 \mathrm{~cm}$ in length, respectively) under the control of a computer. As for the measurements of circular permeability, an Agilent LCR meter was used to measure the impedance $Z=R+j X=R+j \omega L$. The $\mathrm{AC}$ frequency used for the measurements was in range of $\mathrm{f}=1 \mathrm{kHz}-2 \mathrm{MHz}$. The complex circular permeability, $\mu=\mu^{\prime}-\mathrm{j} \mu^{\prime \prime}$, was derived from[6], $\mu^{\prime}=8 \pi \mathrm{X} / \omega 1$ and $\mu^{\prime \prime}=8 \pi(\mathrm{R}-\mathrm{RDC}) / \omega 1$, where RDC, the DC resistance, $1=10 \mathrm{~cm}$, the length of the measured segment of the sample. 


\section{Results and Discussion}

The evolutions of low-field cocervity, $H_{\mathrm{C}}$, determined from the measured longitudinal hysteresis $M(H)$ loop, and DC circular permeability, $\mu_{\mathrm{DC}} \mu_{0}$, deduced by $\mu_{\mathrm{DC}}=\mu^{\prime}(f \rightarrow 0)$, with the annealing current, $j_{\mathrm{a}}$, are plotted in Fig. 1. With increasing $j_{\mathrm{a}}, H_{\mathrm{C}}$ decreases from $5 \mathrm{~A} / \mathrm{m}$ of as-cast sample to a minimum value of $0.5 \mathrm{~A} / \mathrm{m}$ at $j_{\mathrm{a}}=32-36 \mathrm{~A} / \mathrm{mm}^{2}$ and then increases rapidly with elevated $j_{\mathrm{a}}$. In contrast, $\mu_{\mathrm{DC}} / \mu_{0}$ exhibits the opposite trend. This change can be understood by considering the process of nano-crystallization at $j_{\mathrm{a}}=32-36 \mathrm{~A} / \mathrm{mm}^{2}$. The large crystal-grains produced at about $j_{\mathrm{a}}>$ $40 \mathrm{~A} / \mathrm{mm}^{2}$ result in the enhancement of $H_{\mathrm{C}}$.

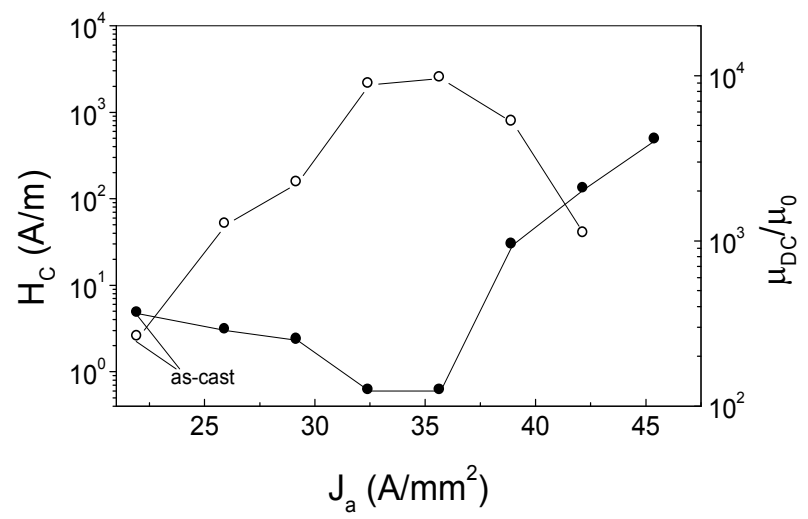

Figure 1 Annealing current $j_{\mathrm{a}}$ dependences of the cocervity $H_{\mathrm{C}}$ and circular permeability $\mu_{\mathrm{DC}} / \mu_{0}$.
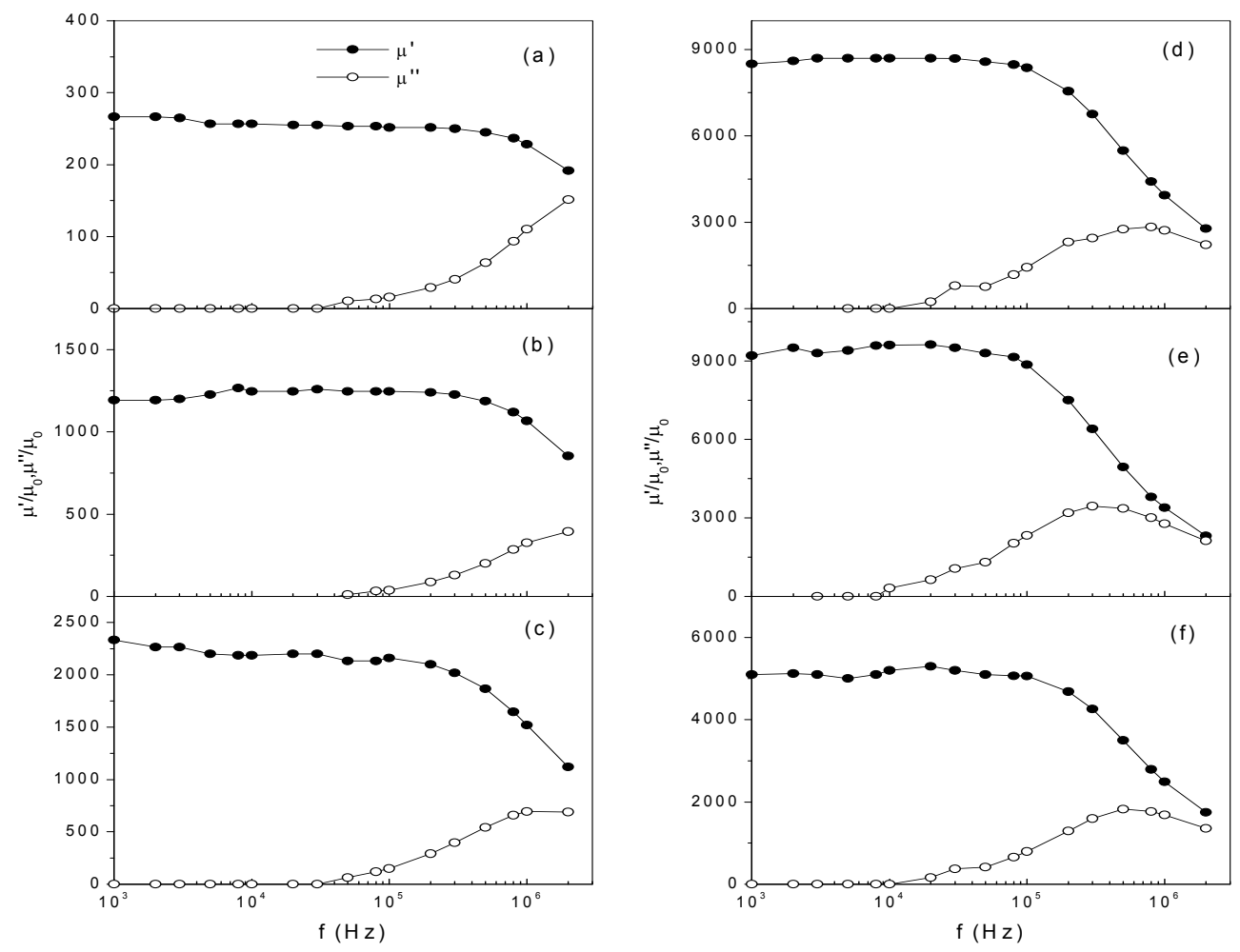

Figure 2 The evolution of magnetic spectra with the annealing current

$$
j_{\mathrm{a}}=0(\mathrm{a}), 26(\mathrm{~b}), 29.2(\mathrm{c}), 32.5(\mathrm{~d}), 35.7(\mathrm{e}) \text { and } 39 \mathrm{~A} / \mathrm{mm}^{2} \text { (f). }
$$

The evolution of magnetic spectra with the current $j_{\mathrm{a}}=0-39 \mathrm{~A} / \mathrm{mm}^{2}$, is shown in Fig. 2. The spectra of all samples show the relaxational feature: from a plateau at low $f$ to a monotonous decrease at higher $f$ of $\mu$, and a increase at low $f$ and then a decrease at high $f$ of $\mu$ ". Theoretically, the relaxation 
frequency $f_{\tau}$ is defined as the value where the maximum of $\mu^{\prime \prime}$ occurs[7]. With increasing $j_{\mathrm{a}}$, the relaxation frequency $f_{\tau}$ decrease monotonously, meanwhile the real part $\mu^{\prime}$ increase from 270 of as-cast sample to 9200 of the best nanocrystalline sample $\left(j_{\mathrm{a}}=35.7 \mathrm{~A} / \mathrm{mm}^{2}\right)$ and then reduce to 5000 of the sample $\left(j_{\mathrm{a}}=39 \mathrm{~A} / \mathrm{mm}^{2}\right)$. The evolutions of magnetic spectra with the annealing time $(t=20$ $600 \mathrm{~s}$ ) for current $j_{\mathrm{a}}=29.2$ and $35.7 \mathrm{~A} / \mathrm{mm}^{2}$ are shown in Fig. 3. The relaxational feature is remained for all samples.
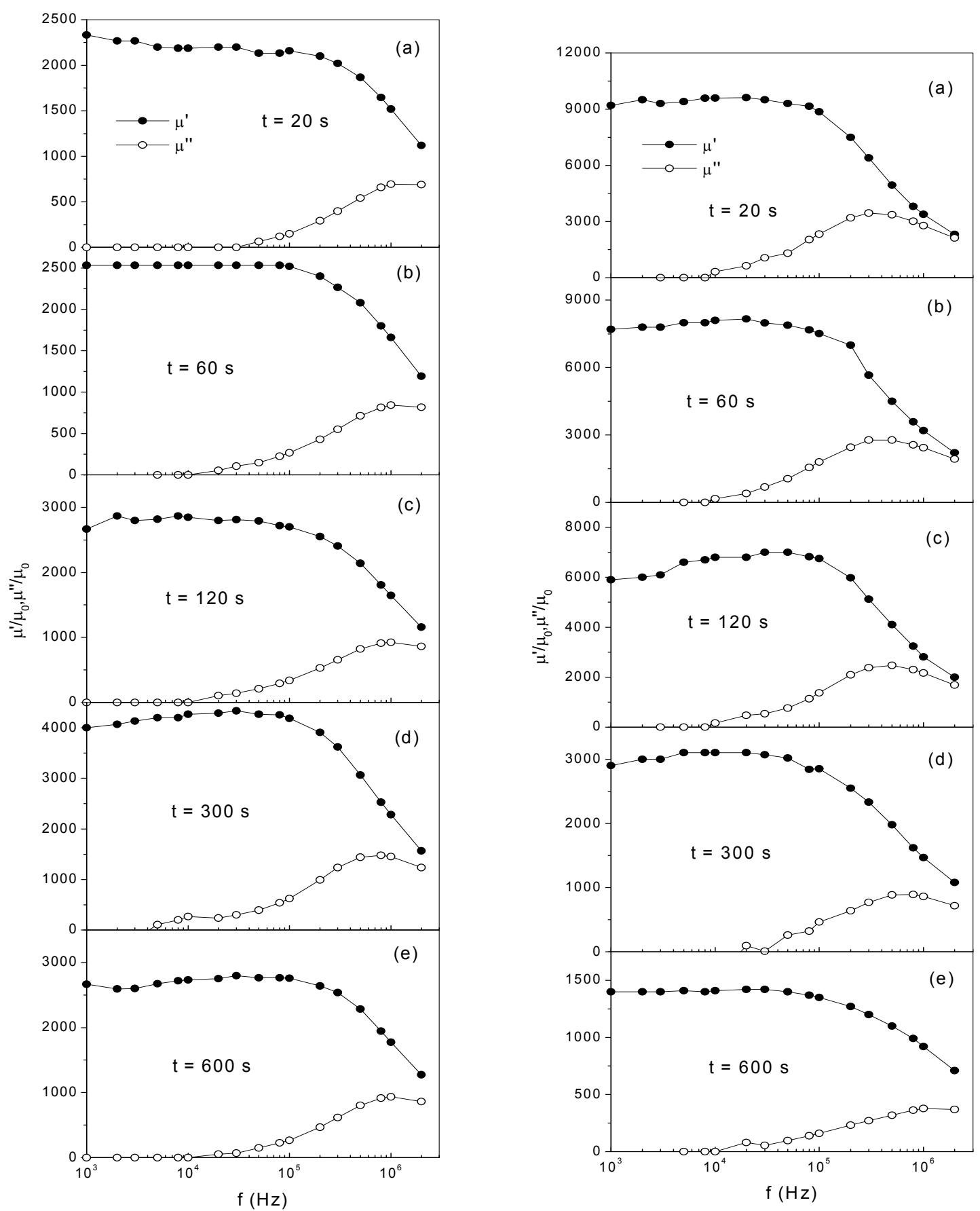

Figure 3 The evolution of magnetic spectra with the annealing time $t$

$$
\text { for current } j_{\mathrm{a}}=29.2 \mathrm{~A} / \mathrm{mm}^{2}(\text { left }) \text { and } j_{\mathrm{a}}=35.7 \mathrm{~A} / \mathrm{mm}^{2} \text { (right) }
$$

For $j_{\mathrm{a}}=29.2 \mathrm{~A} / \mathrm{mm}^{2}$, with increasing $t$, the real part of AC permeability increase gradually from 2200 to 4100 , then reduce to 2700 . It indicates that a proper longer time for a small annealing current 
is helpful to improve the soft magnetic properties. From Fig. 1 we see that the wires annealed at $j_{\mathrm{a}}=$ $29.2 \mathrm{~A} / \mathrm{mm}^{2}$ remain in amorphous state, so a longer time may result in the further relief of internal stress or in the nanocrystallization in the sample. For $j_{\mathrm{a}}=35.7 \mathrm{~A} / \mathrm{mm}^{2}$, with increasing $t$, the real part of complex permeability exhibits a monotonous decrease from 9200 to 1300 , while the relaxation frequency increases gradually. This result indicates that a shorter time is advantageous to get a good soft magnetic alloy. The samples anneald at $j_{\mathrm{a}}=35.7 \mathrm{~A} / \mathrm{mm}^{2}$ consist of nanocrystalline and residual amorphous phases. According to the exchange coupled theory, the coecivity is proportional to $D^{6}, D$ the grain-sized[1]. Therefore, the deterioration of soft magnetic property with longer time can be ascribed to the grow up of the nano-particles.

\section{Conclusions}

In conclusions, the most outstanding magnetic soft properties have been observed in the samples annealed at $\mathrm{ja}=32-36 \mathrm{~A} / \mathrm{mm} 2$ for $20 \mathrm{~s}$ due to the nanocrystallization. All samples exhibit the relaxation-type feature of permeability spectrum. The optimum annealing condition to acquire best magnetic soft properties is a longer or a shorter time for the amorphous or the nanocrystalline alloy, respectively.

\section{Acknowledgement}

This work has been supported by the Project of Scientific Research Plan of Education Bureau of Hebei Province of Reference No. ZD2015201.

\section{References}

[1] G. Herzer, Soft magnetic nanocrystalline materials, Script. Matal. Mater. 33 (1995) 1741-1756.

[2] M. E. McHenry, M. A. Willard, D. E. Laughlin, Amorphous and nanocrystalline materials for applications as soft magnets, Prog. Mat. Sci. 44 (1999) 291-433.

[3] G. Herzer, Modern soft magnets: amorphous and nanocrystalline materials, Acta Materialia 61 (2013) 718-734.

[4] C. Gomez-Polo, Structural and magnetic properties of nanocrystalline $\mathrm{Fe}_{73.5-\mathrm{x}} \mathrm{Co}_{\mathrm{x}} \mathrm{Si}_{13.5} \mathrm{~B}_{9} \mathrm{CuNb}_{3}$ alloys, Phys. Rev. B 65 (2001) 024433.

[5] Y. H. Ding, X. Liu, S. S. Zhao, Y. Long, R. C. Ye, Y. Q. Chang, F. R. Wan, High-temperature AC magnetic properties of nanocrystalline Finemet alloys with Co addition, Acta Metall. Sin. (Engl. Lett.) 20 (2007) 327-333.

[6] D. X. Chen, J. L. Munoz, AC Impedance and Circular Permeability of Slab and Cylinder, IEEE Trans. Magn. 35 (1999) 1906-1923.

[7] S. B. Liao, Ferromagnetism, Science Publishing House, Beijing, 1988 (in Chinese). 